\title{
E-LEARNING STRATEGIES TO IMPROVE THE STUDENTS’ ENGAGEMENT
}

\author{
Ilie GLIGOREA, Ghiță BÂRSAN, Romana OANCEA, Nicolae MORO \\ “Nicolae Bălcescu" Land Forces Academy, Sibiu, Romania \\ iliegligorea@gmail.com, ghbarsan@gmail.com, \\ oancea.romana@gmail.com, nicu.moro@yahoo.com
}

\begin{abstract}
With the right approach and strong enough motivation, any teacher can make attractive learning be a modern and rewarding learning environment that encourages, engages and motivates students to achieve long-term learning success. The study carried out in this article aims to analyze student engagement by taking into account attendance logs, reviewing the content and grades obtained in a technical course of a number of 102 individuals. The collected data were processed in the customized / individualized reports extracted from the Moodle platform. The results of this study highlight the importance of teachers' involvement in creating and adapting content so that students are directly involved in learning, remain active and motivated. The result of the study underlines the elements that can be used for increased students' engagement.
\end{abstract}

\section{Keywords: student engagement, student learning, e-learning strategy}

\section{The topicality of the proposed research}

Students' engagement is a very important aspect that can be used by the professors to increase the student's degree of attention, curiosity, passion, interest, or other factors [3]. Engagement is associated with student achievements [17], and the variables through which the student engagement can be analyzed could be measured by his/her obtained results. It can be said that the higher the result obtained in the end, the greater the student's interest and implicitly engagement. There is no unanimously accepted definition for engagement, but student effort can be measured by a number of factors in the category of behavioral, cognitive and affective indicators [3].

If aspects related to student behavior can be observed erroneously in the traditional space, during online courses the teacher can use digital tools, or digital technology to determine more accurately the level of involvement. Then, depending on the level of engagement of each student, the teacher can adopt the appropriate strategy. In other words, during online courses, the aspects that define student's engagement attention, interaction [22], curiosity, and interest can be measured or estimated with a high degree of accuracy using the learning management system (LMS) [21].

The student's attention, the behavioral factor, during the online classes can be measured by analyzing the marks obtained by the student at the compulsory quizzes at the end of the course or by grading the work tasks during the seminars. The interaction of the cognitive factor during online courses can be measured by the student's attitude and interventions in the virtual space, and their interest, an effective indicator, can be measured by the time spent studying the learning objects provided on the platform. These elements can also be observed in the traditional space, but not always for all students, and a simple 
observation can be difficult to be quantified precisely [19].

The student engagement for e-learning can be improved if the professors consider some aspects when they project learning contents and strategies [4], [9], [10], [12]. These aspects are related with the students' learning styles (visual, auditory, kinesthetic, concrete versus abstract, sequential versus random), the degree of students' familiarity of the material and the prior students' knowledge, the difficulty of the topics and the emotional aspect in that day or in general.

The learning styles have been changed over the time and in general, they are correlated with the characteristics of the generation. For instance, the $\mathrm{Z}$ generation was born with technology and in terms of education they prefer more interactive and visual content [15]. The generation $\mathrm{Y}$ is represented by highly visual learners too and they prefer to learn by using learning strategies and learning styles [22].

A Google Trends analysis since 2011 demonstrates the growing interest in "adaptive learning”, "adaptive technology" and "student engagement" (figure 1). Numbers represent search interest relative to the highest point on the chart for the given region and time. A value of 100 is the peak popularity for the term. A value of 50 means that the term is half as popular. A score of 0 means there was not enough data for this term.

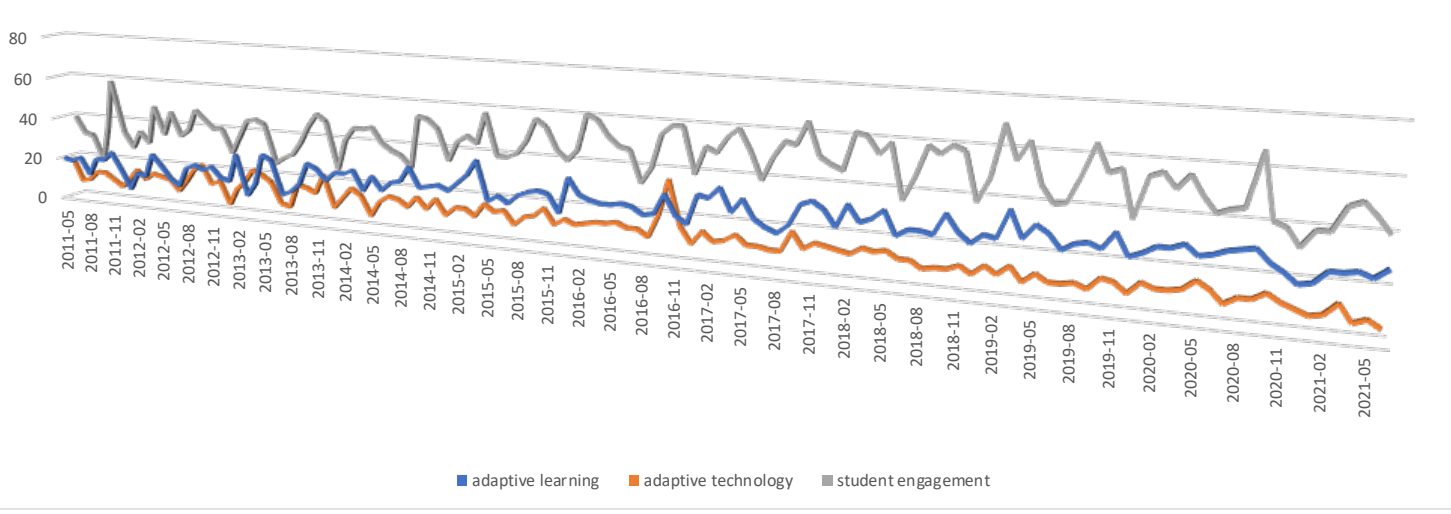

Figure 1: Google trends analysis

Lately, especially during the COVID-19 pandemic period, attention has focused on strategies leading to increased student engagement [5] because student engagement is considered to improve student performance, increases student satisfaction and retention, and last but not least helps to create connections and a good understanding [1],[2],[6] [13], [14],[16], [21].

The three dimensions of student engagement - emotional, cognitive, and behavioral can be assessed more or less automatically during online sessions. Engagement in terms of behavioral terms draws the idea of participation [7] and can be measured by participating in activities, including extracurricular activities, and by submitting the assignment tasks [8], [18]. Creating an emotional climate of learning is the teacher's responsibility and positive / negative emotions can be evaluated from the interpretation of the language used by students during synchronous meetings, from the language used in comments, in work tasks (essay) but also by detecting facial expression [8], [11]. A positively appreciated climate by students can contribute to the increase of interest and implicitly to the achievement of the objectives set by the course. The positive climate can be achieved by designing the course and using the appropriate resources for the user's profile. In addition, students' emotional status can be identified at the end 
of the course through a feedback completed by learners. In terms of cognitive engagement, focus, attention, creative thinking are important factors [8].

Level of student engagement can be measured automatically with digital tools (log-files, computer vision and sensor data analysis) because technology allows to identify more accurately the student's perception of content, if learning objects, resources and activities are properly designed. There are numerous studies in which students' engagement is also measured semiautomatically (or manually (self-reporting or observational checklist) [8].

As methods of data analysis, log-files are analyzed in the paper in order to increase the interest and implicitly students 'engagement. Depending on the identified issues, various strategies will be applied to increase learners' engagement. In a learning management system (LMS) students' actions are saved in log files and they can be valuable sources of analysis. Items such as [8] can be monitored through log-files: number of resources accessed, average time spent on a resource, number of questions answered correctly, questions answered incorrectly, etc., number of interventions, total times spent on learning object or activity, number of forums posts, average time etc., indicators that can be improved, if necessary, by adopting the right strategies and by achieving the objectives pursued.

The study emerged as a necessity to review and redesign the contents because there was a lack of interest and involvement from students. If in the first weeks of online teaching using the web conferencing software was interesting for students, the enthusiasm of students decreased as online conferences began to be used in all subjects and thus, they had to spend many hours daily in front of the computer screen.

\section{Research methodology approached}

102 students, aged between 20 and 26, were chosen to analyze the students' interest in a course. All students have broadly the same generation characteristics - they are digital natives, multitasking and prefer to be connected online, especially to social networks, all the time.

For the first two weeks, with two synchronous meetings in the conference module each week, learning books were used to monitor the student's time on the resource. The book resources (figure 2) consisted of several pages, divided into chapters, and the average time required to study and read for each chapter or subchapter did not exceed 5 minutes.

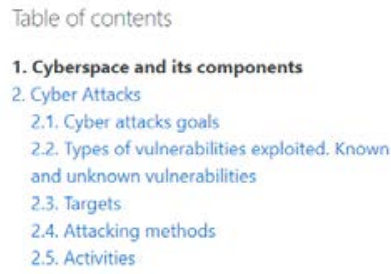

Figure 2: Example of Book resource

During the synchronous meetings, the students were present, but many of them did not have any intervention. In addition, participation in synchronous meetings could be without the webcam turned on.

From the logs obtained automatically from LMS, there were analyzed: learning resources accessed by students, time spent on the platform, accessing at short intervals, the degree of load of tasks and the results obtained in intermediate tests. During the synchronous meetings, the students were present, but many of them did not have any intervention during the discussions.

\section{Result and discussions}

At the results obtained by the students in the evaluation test given after two weeks, a non-correlation was observed between the intermediate results obtained by them and the time spent on learning resources or synchronous meetings. A possible explanation for the lack of correlation between the intermediate results obtained and time - the resources could be accessed and then the student could leave the computer and / or access other pages. The 
correlation was identified between solving the tasks and the marks obtained.

\section{Studets' mark distribution}

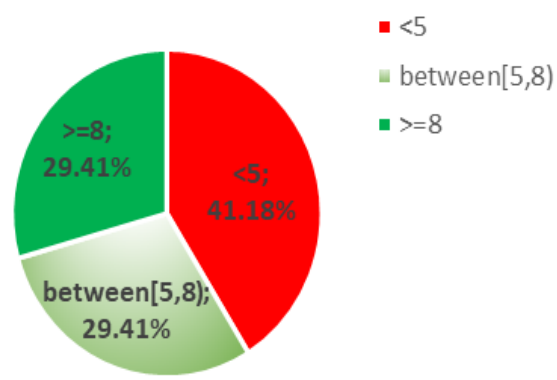

Figure 3: Students' marks distribution first test

The results obtained by students can be considered a measure of the degree of interest. It can be seen that a large number of students were not interested and the reasons for this are influenced by both direct and indirect factors - isolation, lack of socialization (figure 3 ).

Starting from the study conducted by Chen E. et all [5] in which students showed interest in integrating quizzes and polls during the synchronous course, the use of various resources for content design was followed and each synchronous meeting was accompanied by an activity. In addition, book resources have been replaced with lesson-type activities that allow someone to create a set of content and question pages (figure 4). Each student reads the material according to the answer given to the questions - additional pages or materials can be read if the answers are wrong or, certain explanations are omitted if the student knows them.

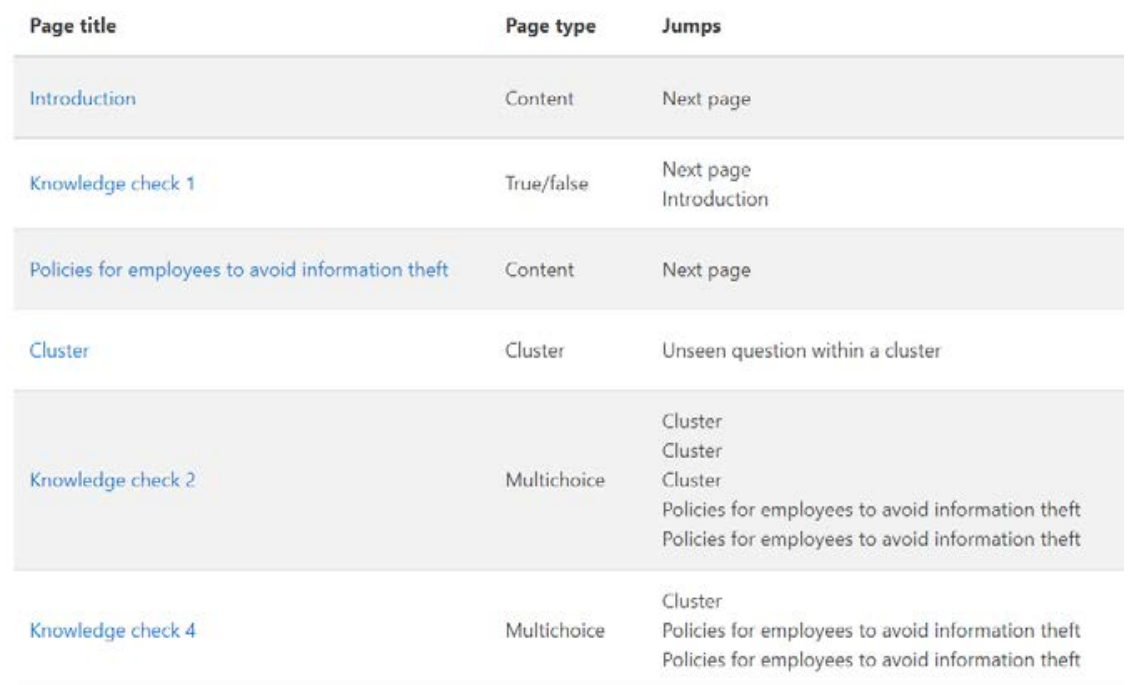

Figure 4: Options: Lesson activity - samples

Diversifying learning resources, direct interaction by integrating mandatory quizzes and initiating short polls, anytime during synchronous sessions, feedback, and mandatory activities at the end of each topic, awarding students with badges and virtual coins - elements of gamification in Moodle, led to increased level of interest for students (figure 5). The distribution of students' scores on assessment demonstrates the importance of interaction and gamification elements in online courses [22]. Stundents' marks distribution

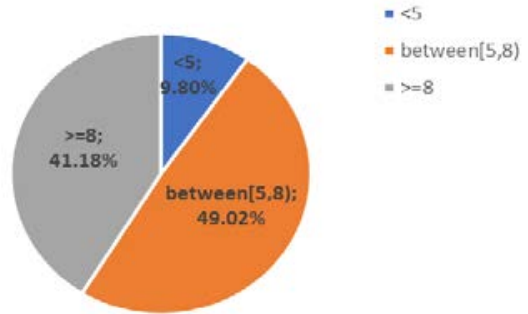

Figure 5: Students' marks - after increasing the level of interaction 
The need for a content adapted to the student's needs was identified depending on his/her performance and profile. In other words, adaptivity factors should also be integrated into the analysis - student performance, level of knowledge, gaps, demographic factors and so on.
The motivation of students during online classes involves quality education in which the student is at the center of the process. There is a constant concern for increasing the level of involvement and identifying the factors that can influence the results (Table 1).

Table 1 Factors that can influence students' engagement

\begin{tabular}{|c|c|}
\hline Factor & Description \\
\hline $\begin{array}{l}\text { Interactive } \\
\text { learning }\end{array}$ & $\begin{array}{l}\text { By dividing into small work groups, teachers can encourage students to interact } \\
\text { with each other through audio-video-text conversations on different concepts } \\
\text { related to the discipline in question, thus strengthening the connection and the } \\
\text { feeling of socialization. }\end{array}$ \\
\hline $\begin{array}{l}\text { Control of the } \\
\text { learning process }\end{array}$ & $\begin{array}{l}\text { Students often feel isolated and disinterested while studying online. One of the best } \\
\text { ways to overcome this is to make them feel appreciated and to put them at the } \\
\text { center of events by creating a flexible learning environment by giving students the } \\
\text { freedom to choose their own tasks but having control in browsing the contents. One } \\
\text { can customize the contents based on the student's learning styles. }\end{array}$ \\
\hline $\begin{array}{l}\text { Possibility of } \\
\text { self-assessment }\end{array}$ & $\begin{array}{l}\text { Quick tests, surveys or questions can help students identify their own strengths and } \\
\text { weaknesses. One way to do this is peer-to-peer assessments, under the guidance of } \\
\text { the teacher, which provide feedback or explanations for the content not yet covered. }\end{array}$ \\
\hline Active learning & $\begin{array}{l}\text { The lack of interactivity in creating the contents of online courses is one of the major } \\
\text { mistakes in online teaching, it makes learning monotonous and limits creativity and } \\
\text { analytical thinking. Therefore, it is important to introduce active involvement in order } \\
\text { to allow students to learn through practical activities. Teachers can allocate various } \\
\text { resources such as workshops, feedback, case studies, projects, discussion forums, } \\
\text { brainstorming activities, etc. related to curriculum concepts. }\end{array}$ \\
\hline Gamification & $\begin{array}{l}\text { There are many ways to incorporate game elements into online learning. One way } \\
\text { to make the teaching process more attractive and fun is to incorporate game } \\
\text { elements, where teachers can give various incentives such as scores, grades, } \\
\text { emoticons, etc. to rate students' results to increase their interest and make them feel } \\
\text { that their efforts are appreciated. Another role of the application of gamification is } \\
\text { to create a closer connection between student and teacher. }\end{array}$ \\
\hline Mobility & $\begin{array}{l}\text { Responsive applications offer the flexibility to learn anywhere, anytime. They can be } \\
\text { used to provide both formal and informal learning. They can be easily customized } \\
\text { (depending on the role, region, competence, or interest of the students). They have the } \\
\text { advantage that they can be easily updated and implemented, and relevant notifications can } \\
\text { be easily customized for students. Also, the contents can be customized for each student } \\
\text { (based on preliminary tests and / or surveys). }\end{array}$ \\
\hline $\begin{array}{l}\text { Using artificial } \\
\text { intelligence } \\
\text { (AI) and } \\
\text { Machine } \\
\text { Learning (ML) }\end{array}$ & $\begin{array}{l}\text { In the teaching-learning process of specialized, technical, and practical disciplines } \\
\text { there is a need to build virtual laboratories, which can solve practical activities in a } \\
\text { virtual environment, using specific techniques of artificial intelligence (AI) and } \\
\text { Machine Learning (ML). In addition, ML can also be used in the construction of } \\
\text { models that estimate the level of students' engagement and / or in determining the } \\
\text { adaptive path for each student. }\end{array}$ \\
\hline
\end{tabular}

\section{Conclusions}

Student engagement and motivation are essential factors especially during online classes, and student outcomes are directly influenced by these factors. The diversity of resources used to create content and activities has led to better results.

Proper design and adaptation of content can increase students' interest in the future if, in addition to monitoring online behavior, offline behavior is also assessed; in other 
words, the combination of SCORM and xAPI standards for better monitoring of student activities. Monitoring student behavior and properly designing content that will lead to increased interest can be improved in the future, when the results of the final exam and the data collected from the logs will be used. ML techniques will be used to estimate the degree of engagement during the semester, and these techniques will have as input data the results obtained from this study [23].

\section{References List}

[1] Banna J, Grace Lin MF, Stewart M, Fialkowski MK. Interaction matters: Strategies to promote engaged learning in an online introductory nutrition course. J Online Learn Teach. 2015 Jun; 11(2):249-261. PMID: 27441032; PMCID: PMC4948751.

[2] Dorel BADEA, Ghiță BÂRSAN, Olga BUCOVEȚCHI, Gabriel MĂNESCU, Crenguța MACOVEI, Dumitru IANCU, Approaching young generation education for security between managerial paradigms specific to standardized need and assumed freedom, Proceedings of the $13^{\text {th }}$ International Management Conference, "Management Strategies for High Performance”, 31st October-1st November, 2019, Bucureşti, România, pp. 326-336, ISSN 2286-1440.

[3] Bond, M., Buntins, K., Bedenlier, S. et al. Mapping research in student engagement and educational technology in higher education: a systematic evidence map. Int $J$ EducTechnol High Educ 17, 2 , 2020, https://doi.org/10.1186/s41239-019-0176-8

[4] Olga Maria Cristina BUCOVEȚCHI, Dorel BADEA, Cristina Petronela SIMION, Business continuity applied to e-education, The 12th International Scientific Conference "eLearning and Software for Education”, Bucharest, April 21-22, 2016, vol. 1, pp. 409-414, DOI: 10.12753/2066-026X-16-059.

[5] Chen, E., Kaczmarek, K.; Ohyama, H., Student Perceptions of Distance Learning Strategies duringCOVID-19. J. Dent. Educ., 2020.

[6] Marin-Marian COMAN, Dorel BADEA, Alexandru LUȚĂ, Enhancing the Management of Scenario Development Process for Simulation Exercises using Dedicated Web-Based Applications,The 14th International Scientific Conference "eLearning and Software for Education”, Bucharest, April 19-20, 2018, vol. 1, pp. 327-332, DOI 10.12753/2066026X-15-064, ISSN 2360-2198.

[7] Tonya Conner, Relationships: The Key to Student Engagement, International Journal of Education and Learning Vol.5, No.1, 2016, pp.13-22 http://dx.doi.org/10.14257/ijel.2016.5.1.02

[8] M. Ali Akber Dewan, Mahbub Murshed and Fuhua Lin, Engagement detection in online learning: a review, in Smart Learning Environments, 6:1, 2019, https://doi.org/10.1186/s40561-018-0080-z

[9] Mircea Fuciu, Hortensia Gorski, Marketing Research Regarding the Usage of Online Social Networking Sites by High School Students, 20th International Economic Conference of Sibiu - Post Crisis Economy - Challenges and Opportunities (IECS), MAY 17-18, 2013, Procedia Economics and Finance, vol. 6, pp. 482-490, 2013, ISSN: 2212-5671, doi:10.1016/S2212-671(13)00166-4

[10] Giurgiu, L., Bârsan, Gh., Mosteanu, D., The Technical Dimension of Knowledge Management in the Context of Learning and Training, The 9th International Management Conference, Management and Innovation for Competitive Advantage ICM 2015, November 5-6, Bucharest University of Economic Studies in partnership with Management Academic Society in Romania 
[11] Hewson, E.R.F. Students' Emotional Engagement, Motivation and Behaviour Over the Life of an Online Course: Reflections on Two Market Research Case Studies, in Journal of Interactive Media in Education, 2018(1), p. 10. DOI: http://doi.org/10.5334/jime.472

[12] Dumitru Iancu, Ghiţă Bârsan, Dorel Badea, Motivation in the Teching-Learning Process, as a Management Improvement Means in the Military Higer Education, The 11th International Management Conference - IMC 2017, The Role of Management in the Economic Paradigm of the XXIst Century, 2-4 nov. 2017

[13] Florence Martin, Chuang Wang, Ayesha Sadaf, Student perception of helpfulness of facilitation strategies that enhance instructor presence, connectedness, engagement and learning in online courses, in The Internet and Higher Education 37, 52-65, 2018

[14] Martin, F. \& Bolliger, D.U. Engagement matters: Student perceptions on the importance of engagement strategies in the online learning environment. Online Learning 22(1), 205-222, 2018, doi:10.24059/olj.v22i1.1092

[15] Mark McCrindle, The ABC of XYZ. Understanding the Global Generations, McCrindle Research Pty Ltd, 2014

[16] Meyer, K.A., Student Engagement in Online Learning: What Works and Why. ASHE High. Edu. Rept., 40: 1-114, 2014. https://doi.org/10.1002/aehe.20018

[17] Parsons, S., Richey, L., \& Parsons, A. W. (2014). Student learning: Engagement \& motivation. Phi Delta Kappan. 95(8), 23-27

[18] Amy L. Reschly and Sandra L. Christenson, Jingle, Jangle, and Conceptual Haziness: Evolution and Future Directions of the Engagement Construct, Handbook of Research on Student Engagement, Springer, 2012

[19] ViewSonic, Measuring Student Engagement with Digital Tools, September 2020, available at https://www.viewsonic.com/library/education/measuring-studentengagement-with-digital-tools/

[20] Taylor, L. \& Parsons, J., Improving Student Engagement. Current Issues in Education (CIE), 14(1). ISSN 1099-839X, 2011, Retrieved from http://cie.asu.edu/

[21] Wang, F.H., An exploration of online behaviour engagement and achievement in flipped classroom supported by learning management system. Computers \& Education, 114(1), 79-91. Elsevier, 2017

[22] Ragesh Raju, SathyendraBhat, ShreerangaBhat, Rio D’Souza, Athokpam Bikramjit Singh, Effective Usage of Gamification Techniques to Boost Student Engagement, Journal of Engineering Education Transformations, Volume 34, January 2021, Special issue, eISSN 2394-1707

[23] https://www.smartsparrow.com/what-is-adaptive-learning/ 